\title{
Equivalence in Bilingual Dictionaries
}

\author{
Xiaomei $\mathrm{Yu}^{1}$ \\ ${ }^{1}$ Guangdong University of Foreign Studies \\ Correspondence: Xiaomei Yu, Guangdong University of Foreign Studies, Baiyun District, Guangzhou, \\ Guangdong, China.
}

Received: September 27, 2020

Accepted: October 20, 2020

Online Published: October 22, 2020

doi: $10.5539 /$ elt.v13n12p1

URL: https://doi.org/10.5539/elt.v13n12p1

\begin{abstract}
The task of the bilingual dictionary is to provide lexical units in the source language with equivalents in the target language. Therefore, translation equivalence is of great importance in compiling a bilingual dictionary. This study is an introduction to categories of equivalence in bilingual dictionaries and the causes of non-equivalence. Some methods for translating non-equivalence are also recommended.
\end{abstract}

Keywords: equivalence, non-equivalence, bilingual dictionaries

\section{Introduction}

The basic purpose of a bilingual dictionary is to coordinate with the lexical units of one language those lexical units of another language which are equivalent in their lexical meaning (Zgusta, 1971:294). The bilingual lexicographers have to adopt equivalence principles in bilingual translation. However, it is not frequent that the lexical meanings of the two lexical units are absolutely identical. This article is an introduction to the three categories of equivalence: complete equivalence, partial equivalence, and non-equivalence. Causes of non-equivalence are analyzed from two aspects: linguistic differences and cross cultural differences. Methods for translating bilingual non-equivalence are also recommended, such as calque translation, free translation and transliteration.

\section{Relevant Studies on Categories of Equivalence}

Equivalence means the relationship between two lexical units from two languages, and they share the same meaning.

The nature of languages is universal and identical. Although languages have their own characteristics, equivalence relationship can be built between two languages in means of translation. Otherwise, communication will not be possible.

There are mainly three types of equivalence: complete equivalence (also called absolute equivalence), partial equivalence and non-equivalence.

\subsection{Complete Equivalence}

Complete equivalence requires that "the lexical meaning of the two lexical units be absolutely identical in all components (designation, connotation, range of application)" (Zgusta, 1971: 312). Complete equivalents mainly exist in the domain of scientific terminologies (Chen, 2018). Most of the complete equivalents have a single meaning.

1) allergy 过敏症

2) globalization 全球化

3) Golden Gate Bridge 金门桥

4) Internet 因特网

In the examples above, the two lexical items share the same meaning. They are complete equivalents. They have designative functions, do not have or have little connotative or emotional meaning, and perform a weak grammatical function. Therefore, most of the complete equivalents are found in the field of scientific terminologies, such as proper nouns, technical terms, and new scientific and technological terms. 


\subsection{Partial Equivalence}

Partial equivalence means the lexical meaning of the lexical unit of the target language covers only a part of the lexical meaning of its counterpart in the source language.

Partial equivalence is the most common phenomenon in bilingual dictionaries. In terms of practical dictionary compilation, there are eight kinds of partial equivalence:

1) Identical linguistic symbols with different conceptual meanings.

(5) a. 娘(Chinese) mother

b. 娘(Japanese) daughter

(6) a. phonologie (Germany) 音位学

b. phonology (English) 音系学

In (5), both Chinese and Japanese have the same linguistic form “娘”, but the former means "mother", while the latter means "daughter". Similarly, in (6), phonologie (Germany) and phonology (English) also have different meanings though they are in the same linguistic form. These lexical units are identical or similar in linguistic form but have different meanings. Therefore, we call them "false friends".

2) Identical linguistic symbols with different designative domains.

(7) 肉 meat

In (7), “肉"in Chinese means the flesh of both man and four-footed animals and birds for food, while "meat" in English just means the flesh of four-footed animals and birds used for food. The two lexical items have different designative domains.

3) Identical linguistic symbols with different registers. For example:

(8) a. vendre (French) 卖

b. vend (English) 卖地、卖不动产

4) Identical conceptual meaning with different associative meanings. For example, "baiser" in French is associated with "love and sex", while "kiss" in English is associated with "love and friendship".

5) Identical conceptual meaning with different connotative meanings.

(9) a. hot 热的

b. The song is hot. 这首歌很流行。

In sentence 9b, “hot” does not mean “热的” but “流行的”. We can see more examples. "a white lie” means “一 个善意的谎言”; “dry white wine” means “无甜味的白葡萄酒”.

6) Identical conceptual meaning with different collocational meanings. For example, “have tea” means “喝茶”; “have meetings" means “开会”; “have time” means “有时间”.

7) Identical designative meaning with different metaphorical meanings. For example, “蝙蝠” in Chinese is a symbol of good luck and happiness, while its counterpart "bat" in English is a symbol of ugliness and cruelty.

8) Identical connotative meaning with different conceptual meanings. For example:

(10) 乱七八糟 at sixes and sevens

(11) 挥金如土 spend money like water

(12) 缘木求鱼 to milk the bull

\subsection{Non-Equivalence}

Non-equivalence means there are no equivalents in the target language for some lexical units in the source language.

Non-equivalence is an obstacle to communication and translation. It is a difficult problem for bilingual lexicographers to deal with. 


\section{Causes of Non-Equivalence}

The phenomenon of non-equivalence is caused by linguistic differences and cross-cultural differences.

\subsection{Linguistic Differences}

Linguistic symbol is arbitrary and conventional. It is very difficult find equivalents in form between two languages. For example, alliteration is a figurative speech often used by English writers or poets. But it is impossible to find in Chinese equivalents which have the same linguistic functions as alliteration.

The phenomenon of non-equivalence can also be found in non-designative words. We call these words functional or grammatical words. For example:

(13) the art [定冠词]1指谈话双方都知道或能体会到的特定的人或事物]

(A New English-Chinese Dictionary: the)

We can see another example. In Chinese, the prefix “老” does not have designative functions. Only when it goes with other words can it have lexical meanings. For instance, “老虎”, “老鹰”, and “老鼠”refer to animals; “老 大”, “老二”, and “老么”refer to seniority among brothers and sisters; “老张” and “老王” refer to addresses. We cannot find in English the equivalent of the prefix “老”.

\subsection{Cross-Cultural Differences}

Nearly all the problems of equivalence are caused by the anisomorphism of language (Zgusta, 1971: 296). In other words, non-equivalence is caused "by the differences in the organization of designate in the individual languages and by other differences between languages." (Zgusta, 1971: 294).

Culture-bound words pose very difficult problems for bilingual lexicographers (Zhang, 2019). Social factors such as natural environment, history, people's thinking mode, and production and life should be taken into consideration in practical bilingual translation.

(14) Beaujolais n. a type of French red wine 薄若莱葡萄酒(一种法国葡萄酒)

(15) 太极 taichi a kind of traditional Chinese shadow boxing

The two words "Beaujoblai" and “太极” are particular to French culture and Chinese culture respectively. We can see more culture-bound words in Chinese such as “粽子”, “铁饭碗”, “跑龙套”, “炕”, “吒头”, “华表”,“二 胡”,“四合院” and the like.

Legends and mythology are another source of culture-bound words. For example:

(16) an Achilles' heel the weak or vulnerable point of a person (organization, country, etc.) 唯一致命的弱 点

(17) 白骨精 the White Boned Demon, an evil spirit who often took the guise of a charming young woman in the novel Pilgrimage to the West.

Because of different modes of production and life, descriptions of the world in different languages are not the same. For example, in Eskimo, snow plays an important role, and there are more than ten words about snow.

\section{Methods for Translating Non-Equivalence in Bilingual Dictionaries}

Since the problem of non-equivalence causes an obstacle to communication, bilingual lexicographers have been trying to settle it. Some methods have been recommended to solve the problem of non-equivalence in bilingual dictionaries.

1) Detailed explanation

"The meaning of the respective lexical unit of the source language is described by an explanation which is similar to the definition of a monolingual dictionary but is worded in the target language." (Zgusta, 1971: 295).

For example, “阿 Q" means the main character in Lu Xun's The True Story of A Q, a backward peasant who interprets his defeats as his moral victories.

2) Transliteration

Transliteration is a mapping from one system of writing into another. For example:

(18) 台风 typhoon

(19) banjo 班卓琴

3) Free translation 
A free translation is a translation that reproduces the general meaning of the original text. It may or may not closely follow the form or organization of the original. For instance:

\section{(20) blue chip n. 1 热门股票 (A New English-Chinese Dictionary)}

4) Calque translation

Calque is a type of borrowing, in which each morpheme or word is translated into the equivalent morpheme or word in another language.

Zhang (2004) divides calque into four types: semantic calque, morphological calque, syntactic calque, and literal translation calque.

(21) semantic calque: 桌面 (a calque of “desktop”)

(22) morphological calque: 卡拉 OK (a calque of “Karaoke”)

(23) syntactic calque: 打破记录 (a calque of "break the record")

(24) literal translation calque: 键盘 (a calque of "keyboard")

\section{Conclusions}

This study discusses the types of equivalence, analyzes the causes of non-equivalence and recommends some methods to deal with the problem of non-equivalence in bilingual translation.

Equivalence principle is very important in bilingual translation. A good understanding of the principle can help lexicographers to do their jobs more effectively and with greater confidence.

\section{References}

Dejun, Li. (2009). Investigation of complete equivalence and non-equivalence and the compilation of Chinese-English bilingual dictionaries. Lexicographical Studies, (2), 55-66. https://doi.org/10.3969/j.issn.1000-6125.2009.02.007

Dingtai, Guo. (2005). The translation of lexemes and illustrative sentences in bilingual dictionaries. Journal of Guangdong University of Foreign Studies, 16, 88-91.

Hui, Zhang. (2019). A China-related English corpus-based study on translation strategies of China-specific words from the perspective of cross-cultural communication (Master's thesis, Guangdong University of Foreign Studies). https://doi.org/10.27032/d.cnki.ggdwu.2019.000523

Kejiang, Feng. (2004). On the phenomenon of equivalence in terms of definitions in bilingual dictionaries: An empirical study (Master's thesis, Guangdong University of Foreign Studies).

Lan, Yang. (2001). Cultural difference and translation (Master's thesis, Xidian University).

Lixin, Xia. (2007). Translation and treatment of non-equivalence in bilingual dictionaries. Journal of Mudanjiang College of Education, (5), 63-64. https://doi.org/10.3969/j.issn.1009-2323.2007.05.033

Longquan, Li. (1999). The relevance of translation equivalence. Journal of Sichuan International Studies University, (2), 82-84.

Shengli, Chen. (2018). A comparative study on translation strategies of China-specific words: Discussion on Chinese culture going international. Forum on Chinese Culture, (2), 12-21.

Yihua, Zhang. (2004). Some consideration on calques and calque translation: Based on English-French-Chinese "specific words". Terminology Strandarization \& Information Technology, (1), 23-26. https://doi.org/10.3969/j.issn.1007-2489.2004.01.006

Yihua, Zhang, \& Heming, Yong. (2007). Contemporary Lexicography. Peking: The Commercial Press.

Zgusta, L. (1971). Manual of Lexicography. The Hague: Mouton. https://doi.org/10.1515/9783111349183

\section{Copyrights}

Copyright for this article is retained by the author(s), with first publication rights granted to the journal.

This is an open-access article distributed under the terms and conditions of the Creative Commons Attribution license (http://creativecommons.org/licenses/by/4.0/). 